\title{
Detection rate of somatostatin receptor PET in patients with recurrent medullary thyroid carcinoma: a systematic review and a meta-analysis
}

\author{
Giorgio Treglia, ${ }^{1,2,3 *}$ Adriana Tamburello, ${ }^{1 *}$ Luca Giovanella $^{1}$ \\ ${ }^{1}$ Nuclear Medicine and PET/CT Center, Oncology Institute of Southern Switzerland, Bellinzona and Lugano, Switzerland; \\ ${ }^{2}$ Health Technology Assessment Unit, General Directorate, Ente Ospedaliero Cantonale, Bellinzona, Switzerland; ${ }^{3}$ Nuclear \\ Medicine and Molecular Imaging, CHUV University Hospital, Lausanne, Switzerland
}

*GT and AT equally contributed to this article sharing the first authorship.

\begin{abstract}
PURPOSE: Several articles have demonstrated the high diagnostic performance of somatostatin receptor positron emission tomography (PET) in patients with neuroendocrine tumours (NETs). On the other hand, only a few studies have evaluated the detection rate (DR) of this imaging method in recurrent medullary thyroid carcinoma (MTC). We aimed to perform a systematic review and a meta-analysis of the DR of somatostatin receptor PET or PET/CT in patients with recurrent MTC to add evidence-based data to this setting. METHODS: A comprehensive computer literature search of studies published in PubMed/MEDLINE and the Cochrane Library Database through May 2017 and regarding somatostatin receptor PET or PET/CT in patients with recurrent MTC was carried out. DR was determined on a per patient-basis. A sub-analysis considering serum calcitonin (Ctn) values was also performed. RESULTS: Nine studies on the diagnostic performance of somatostatin receptor PET or PET/CT in detecting recurrent MTC were discussed in the systematic review. The meta-analysis of these selected studies provided the following DR on a per patient-based analysis: 63.5\% [95\% confidence interval (95\% CI): 49-77]. Heterogeneity among the selected studies was found. DR of somatostatin receptor PET or PET/ $\mathrm{CT}$ increased in patients with higher serum Ctn levels $(83 \%$ for $\mathrm{Ctn}>500 \mathrm{ng} / \mathrm{L})$. CONCLUSIONS: In patients with recurrent MTC, somatostatin receptor PET or PET/CT demonstrated a non-optimal DR which increased in patients with higher serum Ctn values. The diagnostic performance of somatostatin receptor PET or PET/CT in recurrent MTC is lower compared to that of the same imaging method in the majority of NETs.
\end{abstract}

Key words: Gallium, Medullary thyroid carcinoma, Positron emission tomography, PET/CT, Somatostatin, Thyroid cancer

Address for correspondence:

Giorgio Treglia, MD, MSc (HTA), Nuclear Medicine and PET/CT Center, Oncology Institute of Southern Switzerland, Via Ospedale 12, Zip code 6500, Bellinzona, Switzerland; Tel.: +41 918118919; Fax: +41 918118250, E-mail: giorgio.treglia@eoc.ch

Received: 28-08-2017, Accepted: 20-10-2017 


\section{INTRODUCTION}

Medullary thyroid carcinoma (MTC) is a neuroendocrine tumour (NET) originating from the neural crest-derived parafollicular $\mathrm{C}$ cells and accounting for approximately $1-2 \%$ of thyroid cancers. MTC may occur either sporadically or in a hereditary form as a component of the type 2 multiple endocrine neoplasia (MEN2) syndromes. ${ }^{1}$ MTC is frequently an aggressive tumour with a high rate of metastatic spread and recurrence. ${ }^{1}$

The pivotal role of imaging in MTC patients is to determine the optimal treatment. The main treatment for MTC is surgical resection, which is the only strategy offering a potential cure. ${ }^{1}$ Different morphological and functional imaging methods may be used in patients with MTC both in preoperative staging and for detecting persistent/recurrent disease after initial surgical treatment. ${ }^{1}$

In the post-operative setting, conventional morphological imaging modalities can often be negative or inconclusive in the presence of rising serum levels of MTC markers such as serum calcitonin (Ctn). Therefore, functional radionuclide imaging using different radiopharmaceuticals was explored as a way to detect persistent/recurrent MTC, though its role in the initial staging of MTC seems limited. ${ }^{2,3}$ Several radiopharmaceuticals evaluating different metabolic pathways or receptor status can be used as positron emission tomography (PET) tracers in detecting MTC lesions, including fluorine-18-fluorodeoxyglucose $\left({ }^{18} \mathrm{~F}-\mathrm{FDG}\right)$, fluorine-18-dihydroxyphenylalanine $\left({ }^{18} \mathrm{~F}\right.$-DOPA) and somatostatin analogues labelled with Gallium-68. .-8 $^{4-2}$

NETs usually overexpress somatostatin receptors on their cell surface and this represents the rationale for using several somatostatin analogues labelled with the positron emitter Gallium-68 (i.e. ${ }^{68} \mathrm{Ga}$-DOTANOC, ${ }^{68} \mathrm{Ga}$-DOTATOC or ${ }^{68} \mathrm{Ga}$-DOTATATE) for the diagnosis of these tumours by using PET. Somatostatin receptor PET is a valuable diagnostic tool displaying high diagnostic performance in the majority of patients with NETs, as demonstrated by several meta-analyses. ${ }^{9-13}$ Nevertheless, experience with somatostatin receptor PET in recurrent MTC is limited compared to other NETs. Furthermore, while previous evidence-based articles have assessed the detection rate (DR) of PET using ${ }^{18} \mathrm{~F}-\mathrm{FDG}^{14,15}$ and ${ }^{18} \mathrm{~F}-\mathrm{DOPA}{ }^{16,17}$ in recurrent
MTC, a meta-analysis evaluating the DR of somatostatin receptor PET in recurrent MTC is still lacking. Therefore, we aimed to perform a systematic review and a meta-analysis on the DR of somatostatin receptor PET or PET/computed tomography (PET/CT) in patients with recurrent MTC to add evidence-based data to this setting.

\section{METHODS}

This meta-analysis was performed according to the "Preferred Reporting Items for Systematic Reviews and Meta-Analyses" (PRISMA) statement which describes an evidence-based minimum set of items for reporting in systematic reviews and meta-analyses. ${ }^{18}$ Furthermore, specific suggestions for meta-analyses of diagnostic accuracy studies were followed. ${ }^{19}$

\section{Search strategy}

A comprehensive computer literature search of PubMed/MEDLINE and Cochrane Library Databases was conducted to find relevant published articles on the diagnostic performance of somatostatin receptor PET in evaluating patients with recurrent MTC. We used a search algorithm that was based on a combination of these terms: A) medullary OR thyroid and b) Ga OR Gallium OR DOTA* OR somatostatin and c) PET OR positron emission tomography. No beginning date limit was used. The literature search was updated until May $31^{\text {st }}, 2017$. No language restriction was applied. To expand our search, references of the retrieved articles were also screened for additional studies.

\section{Study selection}

Studies or subsets in studies investigating the diagnostic performance of somatostatin receptor PET in patients with recurrent MTC were eligible for inclusion in the qualitative analysis (systematic review). The exclusion criteria were: a) articles not within the field of interest of this review; b) review articles, editorials or letters, comments, conference proceedings; c) case reports.

For the quantitative analysis (meta-analysis) we excluded studies with insufficient data to reassess the diagnostic performance.

Two researchers (GT and AT) independently re- 
viewed the titles and abstracts of the retrieved articles, applying the inclusion and exclusion criteria mentioned above. Articles were rejected if they were clearly ineligible. The same two researchers then independently reviewed the full-text version of the remaining articles to determine their eligibility for inclusion. Disagreements were resolved in a consensus meeting.

\section{Data extraction}

For each included study, information was collected concerning basic study (authors, year of publication, country of origin, study design), patient characteristics (mean age, sex ratio, number of MTC patients performing PET, sporadic or familial form of MTC), technical aspects (device used, type of radiopharmaceutical and mean injected activity, time between radiopharmaceutical injection and image acquisition, image analysis, other imaging methods performed or compared with somatostatin receptor PET such as ultrasound, computed tomography, magnetic resonance imaging, somatostatin receptor scintigraphy, metaiodobenzylguanidine scintigraphy, bone scintigraphy, pentavalent dimercaptosuccinic acid scintigraphy, ${ }^{18} \mathrm{~F}$-DOPA PET, ${ }^{18} \mathrm{~F}$-FDG PET) and applied reference standard. For each included study, the number of patients with recurrent MTC detected by somatostatin receptor PET was recorded. Patients evaluated using somatostatin receptor PET before surgery were excluded from the analysis.

\section{Quality assessment}

The 2011 Oxford Centre for Evidence-Based Medicine checklist for diagnostic studies was used for the quality assessment of the included studies. This checklist has five major parts as follows: representative spectrum of the patients, consecutive patient recruitment, ascertainment of the gold standard regardless of the index test results, independent blind comparison between the gold standard and index test results, sufficient explanation of the test to permit replication. ${ }^{20}$

\section{Statistical analysis}

DR of somatostatin receptor PET was calculated on a per patient-based analysis. DR was determined from the number of patients with recurrent MTC (based on increased serum Ctn values after surgery) detected by somatostatin receptor PET or PET/CT (A) and the number of patients performing somatostatin recep- tor PET or PET/CT (B), according to the following formula: $\mathrm{DR}=(\mathrm{A}) /(\mathrm{B})$. Two sub-analyses considering serum $\mathrm{Ctn}$ values $>500 \mathrm{ng} / \mathrm{L}$ and type of study (prospective versus retrospective) were performed. We used a random effect model for statistical pooling of the data. Pooled data were presented with $95 \%$ confidence intervals $(95 \% \mathrm{CI})$. A I-square statistic was performed to test for heterogeneity between studies. Statistical analyses were performed using StatsDirect statistical software version 3.1 (Altrincham, UK).

\section{RESULTS}

\section{Literature search}

The comprehensive computer literature search from PubMed/MEDLINE and the Cochrane Database revealed 241 articles. Reviewing titles and abstracts, 232 articles were excluded: 192 because not in the field of interest of this review, 29 as reviews, editorials or letters, 11 as case reports. Nine articles were selected and retrieved in full-text version..$^{21-29}$ No additional studies were found screening the references of these articles. All nine articles eligible for the qualitative analysis (systematic review) were included in the quantitative analysis (meta-analysis) because all had sufficient data to assess the diagnostic performance of somatostatin receptor PET (Figure 1). The char-

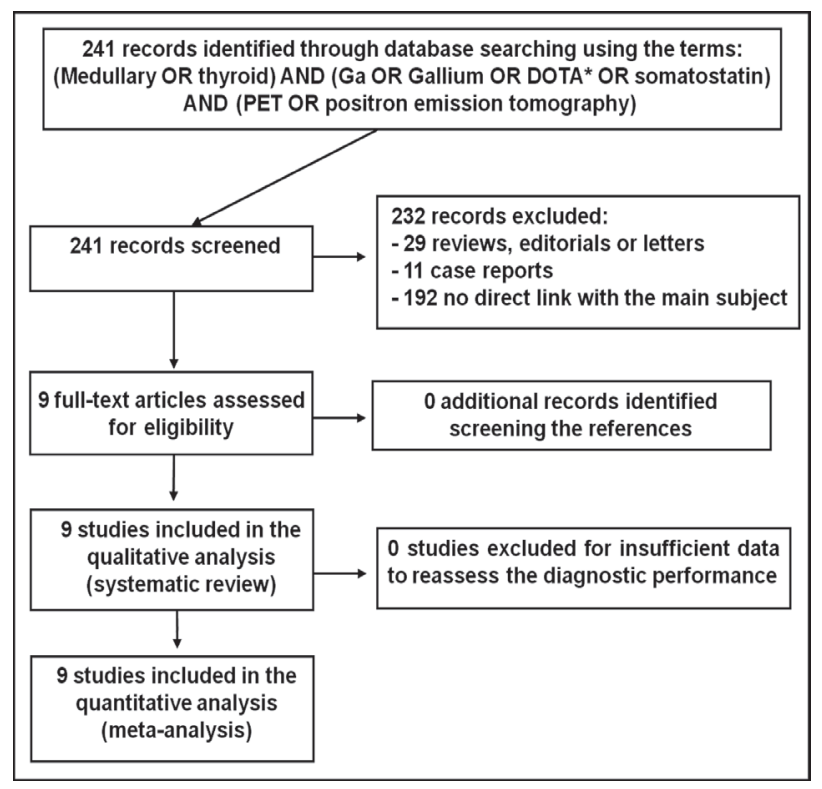

Figure 1. Flow chart of the search for eligible studies on the diagnostic performance of somatostatin receptor PET in patients with recurrent MTC. 
acteristics of the nine selected studies are presented in Tables 1-4.

\section{Qualitative analysis (systematic review)}

Using the database search, nine full-text articles written over the past eight years and including 152 patients with recurrent MTC were selected. ${ }^{21-29}$ Six articles were retrospective $(67 \%)$ and three were prospective (33\%). Several countries of Europe, Asia and America were represented. Concerning the sex ratio, the mean percentage of male patients in the selected studies was approximately $52.5 \%$ (Table 1 ).

Heterogeneous technical aspects among the included studies were found about somatostatin receptor PET. Most studies used a hybrid PET/CT device to evaluate patients with recurrent MTC; only one study used PET alone (Table 2).

Regarding the radiopharmaceuticals used, several somatostatin analogues labelled with Gallium-68 were injected $\left({ }^{68} \mathrm{Ga}\right.$-DOTATATE ${ }^{68} \mathrm{Ga}$-DOTANOC, ${ }^{68} \mathrm{Ga}$-DOTANOC, ${ }^{68} \mathrm{Ga}$-DOTALAN) in the included studies. The injected activity ranged from $72 \mathrm{MBq}$ to $222 \mathrm{MBq}$, while the mean time from radiopharmaceutical injection and PET acquisition ranged from 45 to 90 minutes. The PET image analysis was performed by using qualitative (visual) analysis in all articles considering as abnormal areas of increased radiopharmaceutical uptake beyond the sites of physiological uptake and excretion. Semi- quantitative analysis based on the calculation of maximal standardized uptake values (SUVmax) of the lesions was performed in some articles. All the included articles used a combined reference standard based on pathology or imaging or clinical/biochemical/imaging follow-up data (Table 2).

The other imaging modalities performed in the included studies were quite different (Table 2). Most articles used somatostatin receptor PET or PET/CT in patients with recurrent MTC (based on increasing serum tumour marker levels) and negative conventional imaging techniques.

The diagnostic performance of somatostatin receptor PET in recurrent MTC was usually compared to that of other functional imaging techniques in this setting.

In seven articles somatostatin receptor PET findings in recurrent MTC patients were compared with those of ${ }^{18} \mathrm{~F}$-FDG PET or PET/CT with conflicting results. ${ }^{22-26,28,29}$ Most studies did not find any significant differences in the diagnostic performance of somatostatin receptor PET/CT and ${ }^{18} \mathrm{~F}-\mathrm{FDG} \mathrm{PET}$ or PET/ $\mathrm{CT}, 2^{23-26,29}$ only one study found a s ignificantly higher diagnostic performance of somatostatin receptor PET compared to ${ }^{18} \mathrm{~F}-\mathrm{FDG}$ PET/CT. ${ }^{22}$

Only one study compared the diagnostic performance of somatostatin receptor PET/CT with ${ }^{18} \mathrm{~F}$-DOPA $\mathrm{PET} / \mathrm{CT}$ in recurrent reporting a significantly lower

Table 1. Basic study and patient characteristics

\begin{tabular}{|c|c|c|c|c|c|c|c|}
\hline Authors & Year & Country & Study design & $\begin{array}{c}\text { Patients } \\
\text { performing } \\
\text { somatostatin } \\
\text { receptor PET } \\
\text { or PET/CT }\end{array}$ & $\begin{array}{c}\text { Mean age } \\
\text { (years) }\end{array}$ & \%Male & Type of MTC patients \\
\hline Yamaga et $\mathrm{al}^{21}$ & 2017 & Brazil & Prospective & 15 & 43.6 & $46.6 \%$ & 10 SP, 4 MEN2A, 1 MEN2B \\
\hline Tran et $\mathrm{al}^{22}$ & 2015 & UK & Retrospective & 7 & 45 & $42.8 \%$ & NR \\
\hline Ozkan et $\mathrm{al}^{23}$ & 2015 & Turkey & Retrospective & 22 & 42.9 & $50 \%$ & 17 SP, 4 MEN2A, 1 MEN2B \\
\hline Traub-Weidinger et $\mathrm{al}^{24}$ & 2015 & Austria & Retrospective & 8 & NR & NR & NR \\
\hline Treglia et $\mathrm{al}^{25}$ & 2012 & Italy & Retrospective & 18 & 53.1 & $33.3 \%$ & 16 SP, 1 MEN2A, 1 MEN2B \\
\hline Naswa et $\mathrm{al}^{26}$ & 2012 & India & Prospective & 52 & 44.7 & $73 \%$ & NR \\
\hline Lapinska et al ${ }^{27}$ & 2011 & Poland & Retrospective & 4 & NR & NR & NR \\
\hline Palyga et $\mathrm{al}^{28}$ & 2010 & Poland & Prospective & 8 & 55.6 & $50 \%$ & NR \\
\hline Conry et $\mathrm{a}^{29}$ & 2009 & UK & Retrospective & 18 & 54 & $72.2 \%$ & $18 \mathrm{SP}$ \\
\hline
\end{tabular}

NR: not reported; SP: Sporadic MTC; MEN: multiple endocrine neoplasia. 





Table 3. Detection rate of somatostatin receptor PET on a per patient-based analysis in patients with recurrent medullary thyroid carcinoma

\begin{tabular}{|c|c|c|c|c|c|c|}
\hline \multirow[b]{2}{*}{ Authors } & \multicolumn{2}{|c|}{ All Ctn values } & \multicolumn{2}{|c|}{$\mathrm{Ctn}>500 \mathrm{ng} / \mathrm{L}$} & \multicolumn{2}{|c|}{$\mathrm{Ctn}>1000 \mathrm{ng} / \mathrm{L}$} \\
\hline & $\begin{array}{l}\text { Patients } \\
\text { true positive } \\
\text { at PET }\end{array}$ & $\begin{array}{l}\text { Patients } \\
\text { performing } \\
\text { PET }\end{array}$ & $\begin{array}{l}\text { Patients } \\
\text { true positive } \\
\text { at PET }\end{array}$ & $\begin{array}{l}\text { Patients } \\
\text { performing } \\
\text { PET }\end{array}$ & $\begin{array}{l}\text { Patients } \\
\text { true positive } \\
\text { at PET }\end{array}$ & $\begin{array}{l}\text { Patients } \\
\text { performing } \\
\text { PET }\end{array}$ \\
\hline Yamaga et al ${ }^{21}$ & 13 & 15 & 13 & 13 & 11 & 11 \\
\hline Tran et $\mathrm{al}^{22}$ & 5 & 6 & 5 & 5 & 2 & 2 \\
\hline Ozkan et $\mathrm{al}^{23}$ & 15 & 22 & 11 & 14 & 9 & 10 \\
\hline Traub-Weidinger et $\mathrm{al}^{24}$ & 6 & 8 & NR & NR & NR & NR \\
\hline Treglia et $\mathrm{a}^{25}$ & 6 & 18 & 4 & 9 & 3 & 7 \\
\hline Naswa et $\mathrm{al}^{26}$ & 42 & 52 & NR & NR & NR & NR \\
\hline Lapinska et $\mathrm{al}^{27}$ & 1 & 4 & NR & NR & NR & NR \\
\hline Palyga et $\mathrm{al}^{28}$ & 2 & 8 & 2 & 2 & - & - \\
\hline Conry et $\mathrm{al}^{29}$ & 13 & 18 & 5 & 5 & 4 & 4 \\
\hline
\end{tabular}

Ctn: Calcitonin; NR: Not reported.

DR of somatostatin receptor PET/CT compared to ${ }^{18} \mathrm{~F}$-DOPA PET/CT in this setting. ${ }^{25}$

On the other hand, Yamaga et al. found a significantly higher number of MTC lesions detected by somatostatin receptor PET compared to somatostatin receptor scintigraphy performed with tomographic acquisition (SPECT/CT), ${ }^{21}$ while Ozkan et al. found a significant number of MTC lesions detected by somatostatin receptor PET compared to scintigraphy with technetium- $99 \mathrm{~m}$-labelled pentavalent dimercaptosuccinic acid $\left.{ }^{99 \mathrm{~m}} \mathrm{Tc}-(\mathrm{V}) \mathrm{DMSA}\right){ }^{23}$

Overall, somatostatin receptor PET or PET/CT seems not to accurately map the disease extent in patients with recurrent MTC; however, its provision of complementary information compared to other functional imaging techniques could be useful in identifying patients suitable for consideration of therapy with somatostatin analogues. ${ }^{21-29}$

\section{Quantitative analysis (meta-analysis)}

The DR of somatostatin receptor PET or PET/CT in patients with recurrent MTC on a per patient-analysis ranged from $25 \%$ to $86.7 \%$ with a pooled estimate of 63.5\% (95\% CI: 49-77\%) (Figure 2).

The included studies were statistically quite heterogeneous in their estimate of DR $\left(\mathrm{I}^{2}=69 \%\right)$.

Performing a sub-analysis based on the type of study we found that the pooled DR of somatostatin receptor PET in prospective studies was slightly higher $(68 \% ; 39-91 \%)$ compared to the pooled DR of this method in retrospective studies $(60.1 \%$; 43.7 $75.5 \%$ ), but with significant heterogeneity in both cases $\left(\mathrm{I}^{2}\right.$ was $53 \%$ in retrospective studies and $81 \%$ in prospective studies).

The pooled DR of somatostatin receptor PET or PET/CT was also calculated in 66 patients with serum Ctn levels $>500 \mathrm{ng} / \mathrm{L}$ with a pooled estimate

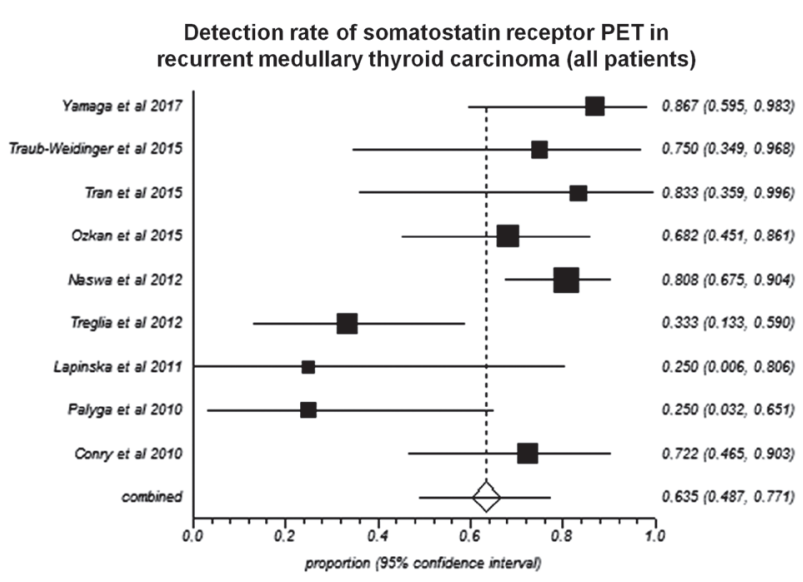

Figure 2. Plots of individual studies and pooled detection rate of somatostatin receptor PET in patients with recurrent MTC on a per patient-based analysis, including 95\% confidence intervals $(95 \% \mathrm{CI})$. The size of the squares indicates the weight of each study. Note the significant heterogeneity among the included studies. 
of $83 \%(95 \% \mathrm{CI}: 66-95 \%)$ and without significant heterogeneity $\left(\mathrm{I}^{2}=49 \%\right)$ (Figure 3$)$.

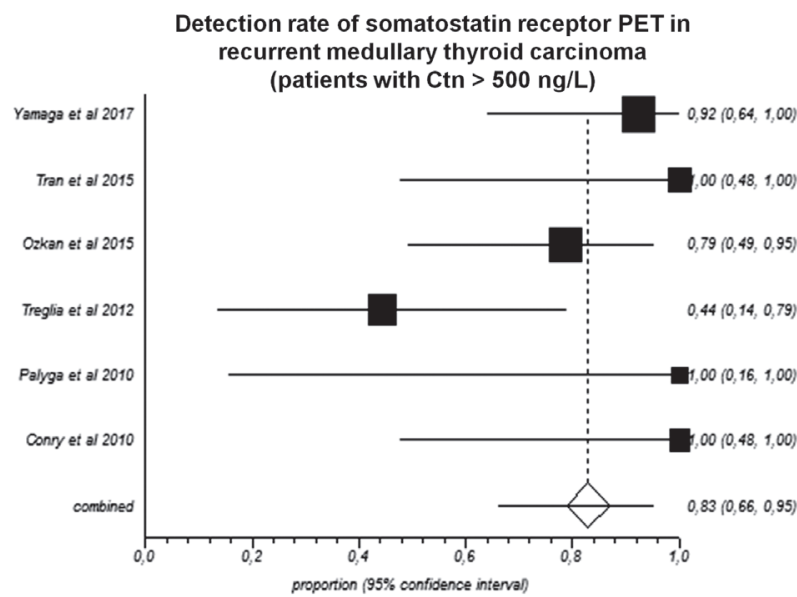

Figure 3. Plots of individual studies and pooled detection rate of somatostatin receptor PET in patients with recurrent MTC and serum calcitonin values $>500 \mathrm{ng} / \mathrm{L}$ on a per patient-based analysis, including $95 \%$ confidence intervals $(95 \% \mathrm{CI})$. The size of the squares indicates the weight of each study.

\section{DISCUSSION}

Early detection of recurrence represents a relevant step in the management of patients with MTC. ${ }^{1}$ According to the American Thyroid Association Guidelines, if the postoperative serum $\mathrm{Ctn}$ level exceeds 150 ng/L MTC, patients should be evaluated by imaging procedures. ${ }^{1}$

To date, several studies have used somatostatin receptor PET in patients with recurrent MTC with conflicting results in terms of DR. ${ }^{21-29}$ These studies have limited power, analyzing only relatively small numbers of MTC patients. In order to derive more robust estimates of diagnostic performance of somatostatin receptor PET in this setting we have pooled published studies. A systematic review process was adopted in ascertaining studies and the quality of the included studies was assessed by using the 2011 Oxford Centre for Evidence-Based Medicine checklist for diagnostic studies (Table 4) ${ }^{20}$ We chose to use the DR as a measure of diagnostic performance

Table 4. Results of the quality assessment of the studies included in the meta-analysis.

\begin{tabular}{|c|c|c|c|c|c|c|}
\hline First author & $\begin{array}{c}\text { Spectrum } \\
\text { of the patients }\end{array}$ & $\begin{array}{l}\text { Consecutive } \\
\text { recruitment } \\
\text { of the patients }\end{array}$ & $\begin{array}{l}\text { Ascertainment } \\
\text { of the gold } \\
\text { standard } \\
\text { regardless of the } \\
\text { index test results }\end{array}$ & $\begin{array}{l}\text { Blind comparison } \\
\text { of the index test } \\
\text { and reference } \\
\text { standard }\end{array}$ & $\begin{array}{l}\text { Enough } \\
\text { explanation } \\
\text { of the index } \\
\text { test to permit } \\
\text { replication }\end{array}$ & $\begin{array}{l}2011 \text { Oxford center } \\
\text { for evidence based } \\
\text { medicine level of } \\
\text { evidence (http:// } \\
\text { www.cebm.net) }\end{array}$ \\
\hline Yamaga et $\mathrm{al}^{21}$ & $\begin{array}{l}\text { Adult patients with } \\
\text { recurrent MTC }\end{array}$ & Yes & Yes & Yes & Yes & 2 \\
\hline Tran et $\mathrm{a}^{22}$ & $\begin{array}{l}\text { Adult patients with } \\
\text { MTC }\end{array}$ & Yes & Yes & No & Yes & 3 \\
\hline Ozkan et al ${ }^{23}$ & $\begin{array}{l}\text { Adult patients with } \\
\text { recurrent or metastatic } \\
\text { MTC }\end{array}$ & Yes & Yes & $\mathrm{N} / \mathrm{A}$ & Yes & 3 \\
\hline $\begin{array}{l}\text { Traub-Weidinger } \\
\text { et } \mathrm{al}^{24}\end{array}$ & $\begin{array}{c}\text { Adult patients with } \\
\text { MTC }\end{array}$ & Yes & Yes & $\mathrm{N} / \mathrm{A}$ & Yes & 3 \\
\hline Treglia et $\mathrm{al}^{25}$ & $\begin{array}{l}\text { Adult patients with } \\
\text { recurrent MTC }\end{array}$ & Yes & Yes & Yes & Yes & 2 \\
\hline Naswa et $\mathrm{al}^{26}$ & $\begin{array}{l}\text { Adult patients with } \\
\text { recurrent MTC }\end{array}$ & Yes & Yes & Yes & Yes & 2 \\
\hline Lapinska et $\mathrm{a}^{27}$ & $\begin{array}{l}\text { Adult patients with } \\
\text { MTC }\end{array}$ & Yes & Yes & $\mathrm{N} / \mathrm{A}$ & Yes & 3 \\
\hline Palyga et $\mathrm{a}^{28}$ & $\begin{array}{l}\text { Adult patients with } \\
\text { disseminated MTC }\end{array}$ & Yes & Yes & No & Yes & 3 \\
\hline Conry et $\mathrm{al}^{29}$ & $\begin{array}{l}\text { Adult patients with } \\
\text { recurrent MTC }\end{array}$ & Yes & Yes & No & Yes & 3 \\
\hline
\end{tabular}

N/A: not available; MTC: medullary thyroid carcinoma. 
of somatostatin receptor PET and PET/CT in patients with recurrent MTC in order to homogenize the results of the various studies. In fact, the studies included in our meta-analysis were quite heterogeneous as regards the definition of false negative and true negative findings of somatostatin receptor PET: while some studies considered patients with increased serum Ctn levels and negative somatostatin receptor PET and other imaging methods as false negative results, conversely, other studies considered the same patients as true negative, thus partially contributing to the wide range of diagnostic performance that can be found in the literature. The DR overcomes these problems because both false negative and true negative results are considered in the denominator using the DR formula.

The findings of our pooled analysis indicate that somatostatin receptor PET or PET/CT has a nonoptimal DR in patients with recurrent MTC on a per patient-based analysis with a pooled DR of $63.5 \%$ (slightly increasing to $68 \%$ taking into account prospective studies only). Therefore, about $40 \%$ of recurrent MTC cases would remain unidentified using this imaging method. On the other hand, it should be considered that somatostatin receptor PET is usually performed in patients with recurrent MTC after negative conventional imaging studies. Therefore, a DR of $63.5 \%$, even if non-optimal, could affect the management of a significant number of recurrent MTC patients.

In order to study the factors which may influence the DR of somatostatin receptor PET in recurrent MTC, a sub-analysis considering serum Ctn values was performed. Our sub-analysis revealed that the DR of somatostatin receptor PET in recurrent MTC improves in patients with higher serum Ctn values $(83 \%$ in patients with serum $\mathrm{Ctn}>500 \mathrm{ng} / \mathrm{L}$ ), suggesting that this functional imaging method could be useful in recurrent MTC patients with advanced disease.

Serum Ctn doubling time is a useful marker of aggressiveness and progression rate in patients with recurrent MTC. Previous meta-analyses have demonstrated that the DR of ${ }^{18} \mathrm{~F}$-FDG PET/CT and ${ }^{18} \mathrm{~F}$-DOPA $\mathrm{PET} / \mathrm{CT}$ increase in patients with recurrent MTC and shorter Ctn doubling time. ${ }^{14,16}$ Unfortunately, a subanalysis correlating the DR of somatostatin receptor
PET to Ctn doubling time in patients with recurrent MTC could not be performed due to insufficient data in the included studies. Future studies should investigate the possible relation between DR of somatostatin receptor PET and $\mathrm{Ctn}$ doubling time in patients with recurrent MTC.

Recent meta-analyses demonstrated a high diagnostic performance of somatostatin receptor PET or PET/CT in patients with NETs with sensitivity and specificity values higher than $90 \%{ }^{10-13}$ Overall, the diagnostic performance of somatostatin receptor PET or PET/CT in recurrent MTC seems to be inferior compared to other NETs due to the variable somatostatin receptor expression in MTC cells. ${ }^{30-34}$

Different PET tracers could be used in detecting recurrent MTC. . $^{5,35,36}$ Comparative analyses between ${ }^{18} \mathrm{~F}$-DOPA and ${ }^{18} \mathrm{~F}$-FDG have shown better results with ${ }^{18} \mathrm{~F}$-DOPA in terms of sensitivity and specificity and a complementary role of the two radiopharmaceuticals in the assessment of recurrent MTC. $., 25,37,38$ The different behaviour of ${ }^{18} \mathrm{~F}-\mathrm{DOPA}$ and ${ }^{18} \mathrm{~F}-\mathrm{FDG}$ in recurrent MTC can be explained by their different uptake mechanisms that, in turn, reflect the different metabolic pathways of NET cells, including MTC cells. ${ }^{18} \mathrm{~F}$-DOPA is a marker of amino acid decarboxylation which is a feature of the neuroendocrine origin of MTC. It can thus be assumed that a higher ${ }^{18} \mathrm{~F}-\mathrm{DOPA}$ uptake is related to a higher degree of cell differentiation, ${ }^{5,16}$ whereas a higher ${ }^{18} \mathrm{~F}-\mathrm{FDG}$ uptake is related to a high-proliferative activity and a poor differentiation. ${ }^{5,14}$ Although ${ }^{18} \mathrm{~F}$-DOPA PET/CT has less prognostic value compared to ${ }^{18} \mathrm{~F}-\mathrm{FDG}$, it can more accurately assess the extent of the disease in patients with residual/recurrent MTC, ${ }^{5,38}$ particularly if early PET imaging is performed. . $^{39,40}$

Comparative analyses between somatostatin analogues labelled with Gallium-68 and ${ }^{18} \mathrm{~F}-\mathrm{FDG}$ have shown the complementary role of these PET tracers in recurrent MTC without statistically significant difference in terms of detection rate of MTC lesions in the majority of studies. ${ }^{23-26,29}$ To date, only one multicentric study compared ${ }^{18} \mathrm{~F}-\mathrm{DOPA},{ }^{18} \mathrm{FDG}$ and somatostatin analogues labelled with Gallium-68, demonstrating that ${ }^{18} \mathrm{~F}$-DOPA PET/CT is the most useful functional imaging method for detecting recurrent MTC lesions in patients with increased serum Ctn levels, performing 
better than ${ }^{18} \mathrm{~F}-\mathrm{FDG}$ PET and somatostatin receptor PET and leading to a change in patient management in a significant percentage of cases. ${ }^{25}$

While ${ }^{18} \mathrm{~F}$-FDG and ${ }^{18} \mathrm{~F}$-DOPA may be prepared industrially (for PET centres without an on-site cyclotron) and delivered ready to use, for labelling somatostatin analogues with Gallium-68, both Germanium-68/Gallium-68 generator and lyophilised peptides are needed..$^{38}$ The easy synthesis process of radiolabelled somatostatin analogues is an advantage supporting their clinical use as PET tracers in NETs. ${ }^{41}$

The limited availability of ${ }^{18} \mathrm{~F}-\mathrm{DOPA}$ and somatostatin analogues labelled with Gallium-68 compared to ${ }^{18} \mathrm{~F}-\mathrm{FDG}$ is probably not a major drawback in the case of a rare cancer such as MTC, a limited number of specialised centres being able to match the demand.

Recent international guidelines for PET/CT imaging of NETs suggest the use of somatostatin receptor PET as a third option after ${ }^{18} \mathrm{~F}$-DOPA and ${ }^{18} \mathrm{~F}-\mathrm{FDG}$ $\mathrm{PET} / \mathrm{CT}$ in patients with recurrent MTC..$^{41}$ Therefore, somatostatin receptor PET/CT could be useful in a minority of patients with recurrent MTC, mainly when neither ${ }^{18} \mathrm{~F}$-DOPA nor ${ }^{18} \mathrm{~F}$-FDG-PET/CT are conclusive in patients with increasing $\mathrm{Ctn}$ levels and negative conventional imaging methods or when treatment with somatostatin analogues is an option. ${ }^{38,41}$ In fact, compared to ${ }^{18} \mathrm{~F}$-FDG and ${ }^{18} \mathrm{~F}$-DOPA PET, somatostatin receptor PET may have a theranostic value as this method could be useful in selecting metastatic MTC patients for therapy with cold or radiolabelled somatostatin analogues to treat metastatic lesions showing high expression of somatostatin receptors. ${ }^{42}$

Some limitations of our meta-analysis should be mentioned. The literature addressing the role of somatostatin receptor PET in patients with recurrent MTC is still limited (only nine studies were included in the quantitative analysis) and this could limit the statistical power of our analysis.

Heterogeneity between studies may represent a potential source of bias. The included studies were statistically heterogeneous in their estimates of DR. This heterogeneity is likely to arise through the diversity of methodological aspects of the different studies (Table 2). The baseline differences among the patients in the included studies (Table 1) and the study quality (Table 4) may also have contributed to the observed heterogeneity of the results. However, such variability was accounted for in a random effects model in our pooled analysis. ${ }^{19}$ Furthermore, performing the sub-analysis taking into account the serum $\mathrm{Ctn}$ values we found a significant reduction of heterogeneity $\left(\mathrm{I}^{2}<50 \%\right)$.

Publication bias is a major concern in all forms of meta-analyses, as studies reporting significant findings are more likely to be published than those reporting non-significant results. Indeed, it is not unusual for small-sized early studies to report a positive relationship that subsequent larger studies fail to replicate. We cannot exclude a publication bias in our pooled analysis.

We chose to calculate the DR on a per patient-based analysis because most of the authors have adopted this criterion. However, we cannot exclude the potential bias derived from this choice, but there were insufficient data to obtain significant results performing a per lesion-based pooled analysis. Furthermore, it was not possible to perform a sub-analysis comparing PET versus PET/CT because of insufficient data.

\section{CONCLUSIONS}

Overall our systematic review and meta-analysis showed that:

- The literature focusing on the use of somatostatin receptor PET in recurrent MTC is still limited and quite heterogeneous.

- In patients with recurrent MTC somatostatin receptor PET or PET/CT demonstrated a non-optimal DR which increased in patients with higher serum Ctn values.

- The diagnostic performance of somatostatin receptor PET or PET/CT in recurrent MTC is lower compared to that of the same imaging method in the majority of NETs.

- According to recent international guidelines, somatostatin receptor PET/CT should not be a first option for detecting recurrent MTC; however, it could be useful in a minority of patients with recurrent MTC, mainly when neither ${ }^{18} \mathrm{~F}$-DOPA nor ${ }^{18} \mathrm{~F}$-FDG-PET/CT are conclusive in patients 
with increasing Ctn levels and negative conventional imaging methods or when treatment with somatostatin analogues is an option.

\section{AUTHORS' CONTRIBUTION TO THE MANUSCRIPT}

G. Treglia: literature search and review, metaanalysis, content planning and manuscript writing.

A. Tamburello: literature search and review, quality assessment, manuscript writing and language editing.

L. Giovanella: manuscript editing.

\section{ACKNOWLEDGEMENTS}

All authors have made substantial contributions to all of the following: (1) the conception and design of the study, acquisition of data, analysis and interpretation of data, (2) drafting and revising the article, (3) final approval of the submitted version.

\section{COMPLIANCE WITH ETHICS GUIDELINES}

\section{Conflict of interest}

All authors (Giorgio Treglia, Adriana Tamburello and Luca Giovanella) declare that they have no conflict of interest.

\section{Ethical approval}

This article does not contain any studies with human participants or animals performed by any of the authors.

\section{REFERENCES}

1. Wells SA Jr, Asa SL, Dralle H, et al, 2015 Revised American Thyroid Association guidelines for the management of medullary thyroid carcinoma. Thyroid 25: 567-610.

2. Rufini V, Castaldi P, Treglia G, et al, 2008 Nuclear medicine procedures in the diagnosis and therapy of medullary thyroid carcinoma. Biomed Pharmacother 62: 139-146.

3. Rufini V, Treglia G, Perotti G, Leccisotti L, Calcagni ML, Rubello D, 2008 Role of PET in medullary thyroid carcinoma. Minerva Endocrinol 33: 67-73.

4. Trimboli P, Crescenzi A, Saggiorato E, Treglia G, Giovanella L, 2017 Novel acquisitions in the diagnosis of medullary thyroid carcinoma. Minerva Endocrinol
42: $238-247$.

5. Treglia G, Rufini V, Salvatori M, Giordano A, Giovanella L, 2012 PET imaging in recurrent medullary thyroid carcinoma. Int J Mol Imaging 2012: 324686.

6. Treglia G, Giovanella L, Rufini V, 2013 PET and PET/ CT imaging in thyroid and adrenal diseases: an update. Hormones 12: 327-333.

7. Treglia G, Muoio B, Giovanella L, Salvatori M, 2013 The role of positron emission tomography and positron emission tomography/computed tomography in thyroid tumours: an overview. Eur Arch Otorhinolaryngol 270: 1783-1787.

8. Treglia G, Sadeghi R, Del Sole A, Giovanella L, 2014 Diagnostic performance of PET/CT with tracers other than F-18-FDG in oncology: an evidence-based review. Clin Transl Oncol 16: 770-775.

9. Barrio M, Czernin J, Fanti S, et al, 2017 The impact of somatostatin receptor-directed PET/CT on the management of patients with neuroendocrine tumor: A systematic review and meta-analysis. J Nucl Med 58: 756-761.

10. Deppen SA, Blume J, Bobbey AJ, et al, $2016{ }^{68} \mathrm{Ga}-$ DOTATATE compared with ${ }^{111}$ In-DTPA-Octreotide and conventional imaging for pulmonary and gastroenteropancreatic neuroendocrine tumors: A systematic review and meta-analysis. J Nucl Med 57: 872-878.

11. Yang J, Kan Y, Ge BH, Yuan L, Li C, Zhao W, 2014 Diagnostic role of Gallium-68 DOTATOC and Gallium-68 DOTATATE PET in patients with neuroendocrine tumors: a meta-analysis. Acta Radiol 55: 389-398.

12. Geijer H, Breimer LH, 2013 Somatostatin receptor PET/ CT in neuroendocrine tumours: update on systematic review and meta-analysis. Eur J Nucl Med Mol Imaging 40: 1770-1780.

13. Treglia G, Castaldi P, Rindi G, Giordano A, Rufini V, 2012 Diagnostic performance of Gallium-68 somatostatin receptor PET and PET/CT in patients with thoracic and gastroenteropancreatic neuroendocrine tumours: a meta-analysis. Endocrine 42: 80-87.

14. Treglia G, Villani MF, Giordano A, Rufini V, 2012 Detection rate of recurrent medullary thyroid carcinoma using fluorine-18 fluorodeoxyglucose positron emission tomography: a meta-analysis. Endocrine 42: 535-545.

15. Cheng X, Bao L, Xu Z, et al, $2012{ }^{18}$ F-FDG-PET and ${ }^{18} \mathrm{~F}-\mathrm{FDG}-\mathrm{PET} / \mathrm{CT}$ in the detection of recurrent or metastatic medullary thyroid carcinoma: a systematic review and meta-analysis. J Med Imaging Radiat Oncol 56: $136-142$.

16. Treglia G, Cocciolillo F, Di Nardo F, et al, 2012 Detection rate of recurrent medullary thyroid carcinoma using fluorine-18 dihydroxyphenylalanine positron emission tomography: a meta-analysis. Acad Radiol 19: 1290-1299.

17. Rufini V, Treglia G, Montravers F, Giordano A, 2013 Diagnostic accuracy of $\left[{ }^{18} \mathrm{~F}\right] \mathrm{DOPA}$ PET and PET/CT in patients with neuroendocrine tumors: a meta-analysis. 
Clin Transl Imaging 1: 111-122.

18. Moher D, Liberati A, Tetzlaff J, Altman DG, 2009 Preferred reporting items for systematic reviews and meta-analyses: the PRISMA statement. J Clin Epidemiol 62: 1006-1012.

19. Sadeghi R, Treglia G, 2017 Systematic reviews and meta-analyses of diagnostic studies: a practical guideline. Clin Transl Imaging 5: 83-87.

20. Oxford Center for Evidence-Based Medicine checklist for diagnostic studies appraisal. Available at: http:// www.cebm.net. Accessed June 1st 2017.

21. Yamaga LYI, Cunha ML, Campos Neto GC, et al, 2017 (68)Ga-DOTATATE PET/CT in recurrent medullary thyroid carcinoma: a lesion-by-lesion comparison with (111)In-octreotide SPECT/CT and conventional imaging. Eur J Nucl Med Mol Imaging 44:1695-1701.

22. Tran K, Khan S, Taghizadehasl M, et al, 2015 Gallium-68 Dotatate PET/CT is superior to other imaging modalities in the detection of medullary carcinoma of the thyroid in the presence of high serum calcitonin. Hell J Nucl Med 18: 19-24.

23. Ozkan ZG, Kuyumcu S, Uzum AK, et al, 2015 Comparison of ${ }^{68} \mathrm{Ga}$-DOTATATE PET-CT, ${ }^{18} \mathrm{~F}$-FDG PET-CT and 99mTc-(V)DMSA scintigraphy in the detection of recurrent or metastatic medullary thyroid carcinoma. Nucl Med Commun 36: 242-250.

24. Traub-Weidinger T, Putzer D, von Guggenberg E, et al, 2015 Multiparametric PET imaging in thyroid malignancy characterizing tumour heterogeneity: somatostatin receptors and glucose metabolism. Eur J Nucl Med Mol Imaging 42: 1995-2001.

25. Treglia G, Castaldi P, Villani MF, et al, 2012 Comparison of 18F-DOPA, 18F-FDG and 68Ga-somatostatin analogue $\mathrm{PET} / \mathrm{CT}$ in patients with recurrent medullary thyroid carcinoma. Eur J Nucl Med Mol Imaging 39: 569-580.

26. Naswa N, Sharma P, Suman Kc S, et al, Prospective evaluation of 68Ga-DOTA-NOC PET-CT in patients with recurrent medullary thyroid carcinoma: comparison with 18F-FDG PET-CT. Nucl Med Commun 33: 766-774.

27. Lapinska G, Bryszewska M, Fijolek-Warszewska A, Kozlowicz-Gudzinska I, Ochman P, Sackiewicz-Slaby A, 2011 The diagnostic role of 68Ga-DOTATATE PET/ $\mathrm{CT}$ in the detection of neuroendocrine tumours. Nucl Med Rev Cent East Eur 14: 16-20.

28. Pałyga I, Kowalska A, Gąsior-Perczak D, et al, 2010 The role of PET-CT scan with somatostatin analogue labelled with gallium-68 ( ${ }^{68} \mathrm{Ga}$-DOTA-TATE PET-CT) in diagnosing patients with disseminated medullary thyroid carcinoma (MTC). Endokrynol Pol 61: 507-511.

29. Conry BG, Papathanasiou ND, Prakash V, et al, 2010 Comparison of (68)Ga-DOTATATE and (18)F-fluorodeoxyglucose $\mathrm{PET} / \mathrm{CT}$ in the detection of recurrent medullary thyroid carcinoma. Eur J Nucl Med Mol Imaging 37: 49-57.

30. Herac M, Niederle B, Raderer M, et al, 2016 Expres- sion of somatostatin receptor $2 \mathrm{~A}$ in medullary thyroid carcinoma is associated with lymph node metastasis. APMIS 124: 839-845.

31. Woelfl S, Bogner S, Huber H, et al, 2014 Expression of somatostatin receptor subtype 2 and subtype 5 in thyroid malignancies. Nuklearmedizin 53: 179-185.

32. Papotti M, Kumar U, Volante M, et al, 2001 Immunohistochemical detection of somatostatin receptor types 1-5 in medullary carcinoma of the thyroid. Clin Endocrinol (Oxf) 54: 641-649.

33. Zatelli MC, Tagliati F, Taylor JE, Rossi R, Culler MD, degli Uberti EC, 2001 Somatostatin receptor subtypes 2 and 5 differentially affect proliferation in vitro of the human medullary thyroid carcinoma cell line tt. J Clin Endocrinol Metab 86: 2161-2169.

34. Treglia G, Rindi G, Rufini V, 2012, Expression of somatostatin receptors may guide the use of somatostatin receptor imaging and therapy in differentiated thyroid cancer. Hormones 11: 230-232.

35. Treglia G, Aktolun C, Chiti A, et al, 2016 The 2015 Revised American Thyroid Association guidelines for the management of medullary thyroid carcinoma: the "evidence-based" refusal to endorse them by EANM due to the "not evidence-based" marginalization of the role of Nuclear Medicine. Eur J Nucl Med Mol Imaging 43: 1486-1490.

36. Maffione AM, Giammarile F, Rubello D, 2017 SPECT/ CT and PET/CT molecular imaging in medullary thyroid carcinoma. Are we running in the right direction? Eur J Nucl Med Mol Imaging 44: 1692-1694.

37. Treglia G, Castaldi P, Villani MF, et al, 2013 Comparison of different positron emission tomography tracers in patients with recurrent medullary thyroid carcinoma: our experience and a review of the literature. Recent Results Cancer Res 194: 385-393.

38. Slavikova K, Montravers F, Treglia G, et al, 2013 What is currently the best radiopharmaceutical for the hybrid PET/CT detection of recurrent medullary thyroid carcinoma? Curr Radiopharm 6: 96-105.

39. Treglia G, Stefanelli A, Castaldi P, et al, 2013 A standardized dual-phase 18F-DOPA PET/CT protocol in the detection of medullary thyroid cancer. Nucl Med Commun 34: 185-186.

40. Soussan M, Nataf V, Kerrou K, et al, 2012 Added value of early 18F-FDOPA PET/CT acquisition time in medullary thyroid cancer. Nucl Med Commun 33: 775-779.

41. Bozkurt MF, Virgolini I, Balogova S, et al, 2017 Guideline for PET/CT imaging of neuroendocrine neoplasms with (68)Ga-DOTA-conjugated somatostatin receptor targeting peptides and (18)F-DOPA. Eur J Nucl Med Mol Imaging 44: 1588-1601.

42. Salavati A, Puranik A, Kulkarni HR, Budiawan H, Baum RP, 2016 Peptide Receptor Radionuclide Therapy (PRRT) of Medullary and Nonmedullary Thyroid Cancer Using Radiolabeled Somatostatin Analogues. Semin Nucl Med 46: 215-224. 